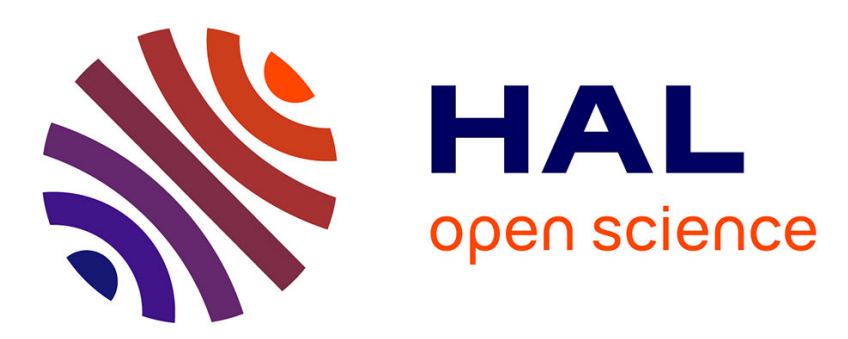

\title{
Inhibitory effects of trans-resveratrol analogs molecules on the proliferation and the cell cycle progression of human colon tumoral cells.
}

Anna-Kristina Marel, Gérard Lizard, Jean-Claude Izard, Norbert Latruffe, Dominique Delmas

\section{To cite this version:}

Anna-Kristina Marel, Gérard Lizard, Jean-Claude Izard, Norbert Latruffe, Dominique Delmas. Inhibitory effects of trans-resveratrol analogs molecules on the proliferation and the cell cycle progression of human colon tumoral cells.. Molecular Nutrition and Food Research, 2008, 52 (5), pp.538-48. 10.1002/mnfr.200700185 . hal-00281570

\section{HAL Id: hal-00281570 \\ https://hal.science/hal-00281570}

Submitted on 9 Jun 2008

HAL is a multi-disciplinary open access archive for the deposit and dissemination of scientific research documents, whether they are published or not. The documents may come from teaching and research institutions in France or abroad, or from public or private research centers.
L'archive ouverte pluridisciplinaire HAL, est destinée au dépôt et à la diffusion de documents scientifiques de niveau recherche, publiés ou non, émanant des établissements d'enseignement et de recherche français ou étrangers, des laboratoires publics ou privés. 
Inhibitory effects of trans-resveratrol analogues molecules on the proliferation and the cell cycle progression of human colon tumoral cells

Anna-Kristina Marel, ${ }^{1,2}$ Gérard Lizard, ${ }^{1,2}$ Jean-Claude Izard, ${ }^{3}$ Norbert Latruffe ${ }^{1,2}$ and Dominique Delmas ${ }^{1,2}$

1 - Inserm U866, Dijon, F-21000, France ;

2 - Université de Bourgogne, Faculté des Sciences Gabriel, Centre de Recherche-Biochimie Métabolique et Nutritionnelle (LBMN), Dijon, F-21000, France ;

3 - Actichem, 121 boulevard du Danemark, BP380, 82003 Montauban Cedex, France.

Whom all correspondence should be addressed:

Dr. Dominique Delmas

Inserm U866,

Centre de Recherche, LBMN

6, Bd Gabriel,

21000 Dijon, France

Phone : 33380396237

Fax : 33380396250

Email : ddelmas@u-bourgogne.fr

Key words: colon cancer, cell cycle, polyphenols, resveratrol, vineatrol. 


\begin{abstract}
Resveratrol may function as a cancer chemopreventive agent. However, few data are available on the antitumoral activities of its dimer, $\varepsilon$-viniferin, also present in human diet. So, the effects of resveratrol, $\varepsilon$-viniferin, of their acetylated forms (resveratrol triacetate, $\varepsilon$-viniferin pentaacetate) and of vineatrol (a wine grape extract) were compared on human adenocarcinoma colon cells. Resveratrol and resveratrol triacetate inhibit cell proliferation and arrest cell cycle. $\varepsilon$-viniferin and $\varepsilon$-viniferin pentaacetate slightly reduce cell proliferation. Vineatrol inhibits cell proliferation and favors an accumulation in the $\mathrm{S}$ phase of the cell cycle. Consequently, resveratrol triacetate and vineatrol could constitute new putative anticancer agents on colon carcinoma.
\end{abstract}




\section{Introduction}

Dietary polyphenols are of great interest due to their antioxidative and anticarcinogenic activities. Indeed, polyphenols are considered chemopreventive agents since they exhibit pharmacological or natural agents to promote the arrest or the regression of cancer process. The impetus sparking of this scientific inquiry was the result of many epidemiologic studies that showed protective effects of plant-based diets on cardiovascular disease and cancer. Among these bioactive compounds, several epidemiological studies [1] revealed that resveratrol may be one of the main wine microcomponents responsible for health benefits. Indeed, resveratrol (trans-3,4',5-trihydroxystilbene) can prevent important pathologies, i.e, vascular diseases, cancers or neurodegenerative processes (see for review [2, 3]). We previously showed that trans-resveratrol, as a chemopreventive agent in colon and other carcinomas, offering renewed interest in grape products and dietary supplements $[4,5]$. One of the major effect of resveratrol could be related to its ability to arrest cell cycle progression $[4,6]$ and/or to trigger tumor cell death by apoptosis [5, 7]. In addition, they are compelling evidences that resveratrol could acts as a chemosensitizer agents with various drugs [8] or cytokines [9]. Nevertheless, its association with other polyphenols must also be considered, since several reports indicated that trans-resveratrol-driven inhibition of cell proliferation is synergized by other polyphenols such as quercetin. Moreover, it was previously reported that a vineatrol preparation, mainly containing two phytochemicals (resveratrol and $\varepsilon$-viniferin ), exhibits a greater antiproliferative effect that resveratrol [10]. Several epidemiological studies (in particular [1]) revealed that resveratrol may be one of the main wine microcomponents responsible for the health benefits (i.e. against vaso-coronary diseases and cancer mortality) in the case of moderate wine consumption. The resveratrol does not seem to be the only bioactive compound present in the wine, its oligomers seem to play an important part. It is thus important to evaluate the biological effects of these molecules in particular on cancerous 
cell lines. In addition, the existence of acetylated phenolic compounds in natural sources is also established, such as acetylated glycosides of flavonoids [11, 12] and resveratrol [13, 14] have been found in plants. These data provide evidence about the existence of acetyl groups in naturally occurring compounds. On the other hand, although the use of phenolic compounds in pharmaceuticals as well as in food preparations is very promising, limitations occur with regard to their weak solubility and stability in a lipophilic environment. The existence of lipophilic derivatives of polyphenols and flavonoids via esterification of the hydroxyl functions with aliphatic molecules can be used as a tool to increase their lipophilicity and therefore improve their intestinal absorption and cell permeability of the compounds [15]. Moreover, structural modification of natural phenolics is expected to produce analogues that may be useful tools to study the structure-activity relationships.

In the present study, we show the potential interest of vineatrol preparation (containing $16 \%$ trans-resveratrol and $20 \% \varepsilon$-viniferin) as an alterative source of resveratrol on human colon adenocarcinoma cells SW480. We compared the effects of trans-resveratrol obtained from chemical synthesis to trans-resveratrol obtained from vine shots, acetylated form of transresveratrol (trans-resveratrol triacetate), $\varepsilon$-viniferin, $\varepsilon$-viniferin pentaacetate and to the vineatrol preparation. We used the resveratrol at $30 \mu \mathrm{M}$, concentration for which we have previously showed that this polyphenol could cause an inhibition of the colon cancer cells proliferation with a blocking in the S phase of the cell cycle [4]. We also showed that this $\mathrm{S}$ phase arrest is accompanied by the induction of an apoptosis process in these cancerous cells $[5,9]$. The oligomers of resveratrol such as viniferin, was also able to block the proliferation of several tumoral cell lines (e.g. leukaemic cells HL60 or human breast cancer cells) to a concentration of $25 \mu \mathrm{M}$ by an action on the cell cycle [16-18]. So, as to be able to compare the antiproliferative activities and their action on the cell cycle of trans-resveratrol analogues by report/ratio with the resveratrol, we chose to compare them compared to an effective 
concentration of $30 \mu \mathrm{M}$ of resveratrol. We demonstrate that resveratrol obtained from the two methods, exerts similar antiproliferative and cell cycle arrest activities on colon cancer cells SW480. In contrast, we show that the oligomer of resveratrol, $\varepsilon$-viniferin, has only a slight effect on cell proliferation but might protect from cell degenerescence. Interestingly, the triacetate form of resveratrol has similar effect than resveratrol. This acetylation could present a great interest to increase the resveratrol absorption without loss of activities same manner as the acetylation of catechins [19]. Indeed, the acetylation of epigallocatechin-3-gallate increases the bioavailability of epigallocatechin in vivo and enhance in vitro his bioactivity [19]. In contrast to resveratrol triacetate, the acetylated form of $\varepsilon$-viniferin exhibit only modest activity on cell proliferation. Moreover, we report that the oligomers of resveratrol and vineatrol preparation were able to involve a pitfall in the colorimetric proliferation MTT test as reported previously with resveratrol on leukemia cells [20]. Although the vineatrol preparation induces a slight increase of MTT-reducing activity due to a direct reduction process, we demonstrate for the first time that vineatrol is able to inhibit proliferation of the human colon adenocarcinoma cell line SW480 and causes cell cycle arrest predominantly at S phase correlated with an increase of DNA replication. Further investigations will reveal if these effects are mainly due to resveratrol and would identify the vineatrol cell cycle targets for new therapeutic strategies.

\section{Materials and methods}

\subsection{Cell line}

SW480 human colon carcinoma cell line obtained from the American Tissue Culture Collection (ATCC, Rockville, MD) were maintained in RPMI 1640 medium, (Biowhittaker Co, Fontenay sous Bois, France) complemented with $10 \%$ fetal calf serum and $2 \mathrm{mM}$ Lglutamine (Biowhittaker). 


\subsection{Drugs, chemical reagents}

Six xenobiotics were used trans-resveratrol obtained from chemical synthesis (Rs) (SigmaAldrich, St Quentin fallavier, France), trans-resveratrol obtained from vine shots (Ra), transresveratrol triacetate (3,5,4'-triacetylresveratrol) (R3A), $\quad \varepsilon$-viniferin $\quad(\varepsilon V), \quad \varepsilon$-viniferin pentaacetate ( $\varepsilon V 5 \mathrm{~A})$ (Actichem, Montauban, France), and vineatrol, a mixture of polyphenols derived from vine shots [10] containing $16 \%$ trans-resveratrol and $20 \% \varepsilon$-viniferin. Briefly, the vine-shoots are ground, extracted with acetone, concentrated, diluted in an ethanol/water mixture. This mixture is then filtered, evaporated and submitted to a combination of preparative HPLC. Resveratrol was purified by flash chromatography and was identified by comparison with a standard from Sigma on a HPLC with a barette of diode detector. Viniferin was purified by flash semi-preparative chromatography then HPLC. The identification was carried out by NMR H and Mass Spectrometry and 2D. A stock solution of these different polyphenols was prepared by dilution in ethanol. In order to compare the activity of the different preparations with trans-resveratrol (Rs), similar stock solution was made for vineatrol preparation with respect to their content in trans-resveratrol, corresponding to 23.8 $\mathrm{mM}$ resveratrol and corresponding to $18.9 \mathrm{mM} \varepsilon$-viniferin.

\subsection{Cell proliferation and viability measurements}

SW480 cells were seeded into $25 \mathrm{~cm}^{2}$ flasks (6x10 cells) in $3 \mathrm{ml}$ of culture medium. After 24h of culture, the cells were treated in triplicate flasks with polyphenols (Rs, Ra, R3A, $\varepsilon \mathrm{V}$ and $\varepsilon \mathrm{V} 5 \mathrm{~A}$ ) used at $30 \mu \mathrm{M}$. Treatment with vineatrol was performed at various concentrations expressed in $\mu \mathrm{M}$ of resveratrol equivalent. All control and treated cells received the same volume of ethanol $(0.1 \%)$. At daily intervals, cells were harvested and the number of cells were quantified by three different methods: i) trypan blue exclusion test which is based on the ability of a viable cell with an intact membrane to exclude the dye trypan blue by using a haemocytometer in microscopic counting, ii) Coulter counter allowing to evaluate the total 
number of cell, and iii) colorimetric methylthiazol tetrazolium (MTT) assay. This last method is based upon the ability of the cells to reduce a tetrazolium salt, 3-(4,5-dimethylthiazol-2-yl)2,5-diphenyltetrazoilum bromide, and to form a blue formazan product by a mitochondrial enzyme, succinate deshydrogenase (SDH) [21]. Therefore, the quantitative colorimetric MTT assay has been widely used to evaluate the effects of drugs on cell growth [22]. After MTT addition $(0.5 \mathrm{mg} / \mathrm{ml})$, the plates were incubated for $3 \mathrm{~h}$. At the end of the incubation period the medium was removed and the converted dye was solubilized with acidic isopropanol $(0.1$ $\mathrm{N} \mathrm{HCl}$ in absolute isopropanol). Absorbance was measured at a wavelength of $570 \mathrm{~nm}$. Results were expressed as percentage of control values.

\subsection{Apoptosis identification}

Apoptosis was identified by staining the nuclear chromatin of trypsinized cells with $1 \mu \mathrm{g} / \mathrm{ml}$ Hoechst 33342 (Sigma-Aldrich) for 15 min at $37^{\circ} \mathrm{C}$. The percentage of apoptotic cells was determined by analyzing 300 cells.

\subsection{Flow cytometric determination of cellular permeability with propidium iodide}

SW480 cells plated in 24-well plates were cultured for $48 \mathrm{~h}$ in the absence or in the presence of polyphenolic compounds. At the end of the incubation time, cells were stained with propidium iodide (PI) which enters cells with permeable plasmic membrane, and stains dead cells only [23]. Fluorescence of PI was collected by using a 590/10 nm bandpass filter and measured on a logarithmic scale. Flow cytometric analyses were performed on Galaxy flow cytometer (Partec, Münster, Germany). Ten thousand cells were acquired for each sample. Data were analyzed with FlowMax software (Partec).

\subsection{Flow cytometric analysis of cell cycle}

Cells were seeded $24 \mathrm{~h}$ before treatment into $25 \mathrm{~cm}^{2}$ flasks. After treatment, the detached and adherent cells were pooled, fixed with ethanol, and stained with PI as previously described [4] for subsequent analyses with a CyFlow Green flow cytometer and the fluorescence of PI was 
detected above $630 \mathrm{~nm}$. For each sample 20, 000 cells were acquired. Furthermore, data were analyzed with MultiCycle software (Phoenix Flow Systems, San Diego, USA); the x axis correspond to the DNA content and the y axis to the number of cycling cells. The maximum value on the y axis is inversely proportional of the altered cells level (non cycling cells) which are excluded by gating.

\subsection{Determination of $\left[{ }^{3} \mathbf{H}\right]$ thymidine incorporation}

DNA synthesis determined by the incorporation of $\left[{ }^{3} \mathrm{H}\right]$ thymidine was performed as previously described [4]. Briefly, the cells were seeded at a density permetting exponential proliferation and were labelled with $1 \mu \mathrm{Ci} /$ well of $\left[{ }^{3} \mathrm{H}\right]$ thymidine (Amersham, France), and the cell lysate was added to scintillation liquid. The radioactivity was determined by using a LS6000IC counter (Beckman, U.S.A.). The results were expressed in d.m.p. per cells.

\subsection{Statistical analysis}

The experiments were repeated at least three times. The data were expressed as the mean \pm S.D. $(n=6)$ of three independent experiments. The significance of differences was established with the Student's test.

\section{Results}

\subsection{Colon cancer cell growth inhibition}

SW480 colon carcinoma cells were exposed to polyphenol compounds (Fig. 1A) such as trans-resveratrol from chemical synthesis (Rs) or from vine shots (Ra); trans-resveratrol triacetate (R3A), $\varepsilon$-viniferin $(\varepsilon \mathrm{V}), \varepsilon$-viniferin pentaacetate $(\varepsilon \mathrm{V} 5 \mathrm{~A})$ and vineatrol (Vinea5) containing $5 \mu \mathrm{M}$ of trans-resveratrol equivalent and $4 \mu \mathrm{M}$ of $\varepsilon$-viniferin (Fig 1B). As revealed by the growth curves (Fig 1B), these compounds have different antiproliferative activities. Indeed, Rs, Ra and R3A at the same concentration $(30 \mu \mathrm{M})$ produced a strong inhibition of cell growth of the cancer cells in time-dependent manner with a complete growth arrest after $24 \mathrm{~h}$ of treatment (Fig. 1B). The percentages of proliferation inhibition induce by the three 
compounds are $85 \%, 87 \%$ and $80 \%$ respectively. The Coulter-counter confirmed the results obtained and show that these compounds exert at $48 \mathrm{~h}$ of treatment a dose-dependent cell growth inhibition (Fig.1C). A second group of compounds was characterized by a slight antiproliferative activity (Fig.1B). It appeared that the SW480 cells exposed to $\varepsilon \mathrm{V}$ and $\varepsilon \mathrm{V} 5 \mathrm{~A}$ at $30 \mu \mathrm{M}$ grew similarly to the control, but at a reduced growth rate and the percentage of cell inhibition is also low with the increase of the concentration (Fig. 1C). The treatment of SW480 cells with Vinea5 showed a similar cell proliferation inhibition to $\varepsilon V$ and $\varepsilon V 5 A$ (Fig. 1B). In fact, vineatrol preparation exerts an antiproliferative activity in a dose- and timedependent manner (Fig. 1C, 1D). The treatment starting with Vinea20 already gave a significant inhibition of cell proliferation (76 \%) after 72h. At a higher concentration, Vinea50 was toxic leading to a decrease of the cell number (Fig. 1D). The dose-dependent antiproliferative effect induced by Rs, Ra, R3A and Vinea was associated with an increase of cell death in dose-dependent manner (Fig. 1E). Indeed, SW480 cells shown an enhancement of cellular permeability with PI after treatment with high concentrations (60 $\mu \mathrm{M})$ of Rs, Ra, R3A and Vinea, whereas it is not the case with $\varepsilon \mathrm{V}$ and $\varepsilon V 5 \mathrm{~A}$ (Fig; 1E). That's why, we used for the following experiments a non toxic concentration of $30 \mu \mathrm{M}$ for the polyphenolic compounds. At this concentration, the proliferation inhibition was due to specific effect of compound and no due to their cytotoxic effect. The dose-dependent proliferation inhibition was confirmed by the colorimetric proliferation MTT test. Indeed, it appeared after the incubation with Rs, Ra, a similar decrease of the cell survivals percentage in a time- and dosedependent manner (Fig. 2A). The percentage of survival cells curves of R3A showed similar profile excepted at $96 \mathrm{~h}$ of treatment with the lower concentration range where the acetate compound exerts an increase of the blue formazan product. Similar results were obtained with the vineatrol preparation (Fig. 2A). The oligomeric polyphenols, $\varepsilon \mathrm{V}$ present no inhibition of proliferation and stimulated the production of the blue formazan like as $\varepsilon V 5 \mathrm{~A}$ (Fig. 2A). In 
previous study, Bernhard et al. [20] have been shown that trans-resveratrol was able to enhanced MTT-reducing activity under growth inhibition in leukaemia cells. This observation was not due to a direct reduction of MTT by resveratrol but appeared to be dependent on the cell type [20]. So, here we also tested if R3A, $\varepsilon V, \varepsilon V 5 A$ and Vinea were able to directly reduce MTT in the absence of cells as compared to vitamin C used as control. We observed that R3A, $\varepsilon \mathrm{V}$ and $\varepsilon \mathrm{V} 5 \mathrm{~A}$, such as resveratrol, do not directly reduce the MTT (Fig. 2B). On the contrary, vineatrol was able to directly reduce in a dose-dependent the MTT although at a lower level that vitamin C (Fig. 2B). So, the MTT test could induce a pitfall to determine the antiproliferative effect of natural compounds such as polyphenols.

As we showed previously, when cultured in the presence of trans-resveratrol, SW480 colon carcinoma cells underwent apoptosis (Fig. 2C). Indeed, cell staining with Hoechst 33342 demonstrated that Rs, Ra, R3A induce an increase in the nucleus size that preceded the appearance of characteristic apoptotic changes, i.e. the condensation and fragmentation of the nuclear chromatin (Fig. 2C). This process was also observed with vinea that it is not the case with $\varepsilon \mathrm{V}$ and $\varepsilon \mathrm{V} 5 \mathrm{~A}$ (Fig. 2C). By using trypan blue staining, we have evaluated the percentage of necrotic cells or apoptotic cells, relative to total cells and we observed a higher level of apoptotic cells with Rs, Ra, R3A and vinea (Fig. 2D).

\subsection{Alteration of cell cycle by polyphenols and vineatrol}

In order to identify the phases of the cell cycle of SW480 cells, we conducted flow cytometric analyses in the presence of different polyphenols. As soon as $24 \mathrm{~h}$ of treatment with Rs, Ra, and R3A marked modifications of the cell cycle were detected at $30 \mu \mathrm{M}$ concentrations which are not cytotoxic (Fig. 3). They were characterized by an accumulation of the cells in the $S$ phase increasing in a time-dependent manner. This gradual accumulation of the cells in the S phase (Fig. 3, Fig.4) showed an increase of $+20 \%$ after $24 \mathrm{~h}$ and reached $+60 \%$ after $72 \mathrm{~h}$ of treatment. At the opposite, $\varepsilon \mathrm{V}$ and $\varepsilon \mathrm{V} 5 \mathrm{~A}$, did not lead to cell cycle 
modifications (Fig. 3, Fig.4) and we observed a normal level of cells in the different phases. With vineatrol (Fig. 5), we observed an increase in the S phase with Vinea5 after 24h of treatment which further increased in a time- and dose-dependent manner (Fig. 5, Fig. 6).

\subsection{Colon cancer DNA synthesis inhibition}

To precise the relationships between the accumulation of the cells in the S phase of the cell cycle and the DNA synthesis in SW480 cells, we measured the $\left[{ }^{3} \mathrm{H}\right]$-thymidine incorporation rate in colon cancer cells which are studied at a density permitting exponential proliferation (Fig. 7). In this study, we do not correlate the cell proliferation inhibition with DNA synthesis because we measured the DNA synthesis after $24 \mathrm{~h}$ of treatment. Conversely to a decrease in DNA synthesis most often associated with an inhibition of cell proliferation, our results showed an increase in the $\left[{ }^{3} \mathrm{H}\right]$-thymidine incorporation per cells treated or not after 24, 48, and $72 \mathrm{~h}$ of treatment with Rs, Ra, R3A and vineatrol (Fig. 7). These observations were in agreement with previous data obtained with hepatoblastoma HepG2 cells [24] and colon carcinoma SW480 cells after treatment with resveratrol [4]. In agreement with the cell cycle modifications, the most important $\left[{ }^{3} \mathrm{H}\right]$-thymidine incorporation per cells increase was found with Rs, Ra and R3A. The lack of effects of $\varepsilon \mathrm{V}$ and $\varepsilon \mathrm{V} 5 \mathrm{~A}$ confirmed that cell cycle and DNA synthesis were not affected by these compounds.

\section{Discussion}

Several epidemiological studies [1] revealed that resveratrol may be one of the main wine microcomponents responsible for the health benefits in the case of moderate wine consumption. The present study demonstrates that resveratrol analogues such as transresveratrol triacetate can be as much active that trans-resveratrol, and the oligomers such as $\varepsilon$ viniferin exhibit an only very slightly effect on cell proliferation and on cell cycle progression of colon cancer cells. A vineatrol preparation containing $16 \%$ of trans-resveratrol and $20 \%$ 
of $\varepsilon$-viniferin presents an antiproliferative activity and an inhibition of cell cycle progression similar to resveratrol at comparable concentration.

It appears that purified trans-resveratrol present similar antiproliferative and cell cycle disturbing effects with trans-resveratrol chemically synthesized, indicating that the extraction and the purification of trans-resveratrol obtained from vine shots did not modified these activities. These results are in accordance with previous observations reporting that chemically synthesized resveratrol favors the accumulation of colon tumoral cells in the S phase of the cell cycle [4]. Furthermore, the acetylation of trans-resveratrol showed a comparable antiproliferative activity by blocking the $\mathrm{S}$ phase of the cell cycle. Thus, our observations fit with data obtained on prostate tumor cell line describing that cell-growth inhibition activities of triacetate and of tributanoate derivatives of resveratrol were similar than those of resveratrol [25]. These results have major interests since an esterification of the three phenol groups could lead to important modifications in the lipophilicity of the molecule and could modify the cellular uptake and consequently involved a best absorption of this molecule without loss of its activities. Indeed, despite an efficient absorption by the organism, resveratrol has unfortunately a low level bioavailability, glucuronidation and sulfation being limiting factors. But recent studies show that the acetylation can enhance biological activities and increase bioavailability of natural compounds such as epigallocatechin-3-gallate [19, 26] or chemical drugs (e.g. declopramide) [27]. As well as this compounds, the acetylation of resveratrol could enhance its bioavailability and increase his antiproliferative effects in vivo. So as to show that acetylation represents an interest to increase the bioavailability of transresveratrol and trans-resveratrol analogues, several studies in vivo will have to be realized to compare times of half life in the plasma, small intestine and colon, respectively. In addition to these studies, experiment on animal models of colon carcinogenesis will have to be realized to test the effect of the acetylated forms. In contrast to resveratrol and to its acetylated form, the 
compounds $\varepsilon \mathrm{V}$, and its acetylated form, $\varepsilon \mathrm{V} 5 \mathrm{~A}$, exhibit only modest antiproliferative activity and no modification of cell cycle. The nearly absence of $\varepsilon \mathrm{V}$ activity on SW480 cells seems to be dependent of the cell type. Indeed, previous studies showed that $\varepsilon \mathrm{V}$ was able to arrest leukaemia cell proliferation, to induce apoptosis, and a cell cycle modification [16]. Moreover, it has been recently described that resveratrol oligomers isolated from seeds of Paeonia lactiflora Pall were capable to inhibit the growth of various cancer cells in a dosedependent manner [17]. It should be of interest to compare the activities of $\varepsilon$-viniferin with $\alpha$ viniferin since its glucosides forms are able to inhibit DNA topoisomerase II [18]. However, the differential sensitivity observed with the MTT test commonly used to measure cytotoxic and/or antiproliferative effects could be due to a pitfall. Indeed, in SW480 cells, we observed that R3A, vineatrol preparation less than $\varepsilon \mathrm{V}$ and $\varepsilon \mathrm{V} 5 \mathrm{~A}$ can induce an increase of the MTTreducing activity. These observations were very important since the MTT test can mask antiproliferative activities and could be a possible pitfall in cell sensitivity determination. Its appears that vineatrol alone is able to reduce directly the yellow tetrazolium leading to an increase of MTT-reducing activity, contrary to $\varepsilon \mathrm{V}$ and $\varepsilon V 5 \mathrm{~A}$. In genistein-treated cells, it was suggested that this increase of MTT-reducing activity could be due to an increase of the cell volume and of the number of mitochondria [28]. Similarly, resveratrol and R3A induce an increase in cell volume (data not shown) and also induce an accumulation of SW480 cells in S phase. Bernhard et al. [20] suggested that this phenomenon was associated with the differentiation process. This hypothesis is supported by the ability of resveratrol to induce differentiation of colon carcinoma cells via nuclear receptor [29]. However, it was not the case with $\varepsilon \mathrm{V}$ and its acetylated form which have no effect the cell volume and differentiation, probably because these polyphenols may interact with the redox activities of mitochondria and consequently contribute to the reduction of MTT. Interestingly, we showed for the first time, that a vineatrol preparation causes a dose- and time-dependent inhibition of colon cancer 
cells which was associated with a stronger arrest of cell cycle progression. Indeed, it appears that vineatrol induce in dose- and time-dependent manner an accumulation of tumoral cells in S phase of cell cycle corresponding to the DNA synthesis. These cellular and biochemical observations appeared to be specific since the concentration (30 $\mu \mathrm{M})$ used is not cytotoxic on SW480 colon cancer cells as shown by the absence of increase permeability to PI. Thus, we considered that cell proliferation arrest is not due to an arrest of DNA synthesis resulting from cell death, but rather to an elongation of the S phase delaying the cell cycle and preventing the cells to enter into the G2/M phase after treatment with Rs, Ra, R3A and vineatrol. At a long time of treatment, we observed a slight decrease of the $\left[{ }^{3} \mathrm{H}\right]$-thymidine incorporation per cells which could be the consequence of cell cycle control deregulation. Thus, the decrease of cell number following a treatment with vineatrol should be due to the cell cycle arrest preventing cell division. Consequently, the G2/M phase disappeared throughout the treatment with vineatrol. It is therefore tempting to speculate that if the cells cannot enter in the phase of division, they undoubtedly will enter in a cell death process. By fluorescence microscopy using Hoechst 33342 we have evaluated the death process. As we shown previously [5], resveratrol induce apoptosis of SW480 colon carcinoma cells, in the same way, its acetylated form and vineatrol preparation can induce apoptosis in the cell line.

Altogether, our data obtained in colon cancer SW480 cells support that resveratrol contained in the vineatrol preparation may be responsible of its effects on proliferation and cell cycle, indicating that this polyphenol mixture may be a convenient and alternative source for the preparation of natural anti-tumoral agents. Furthermore, concerning resveratrol triacetate, our data underline the interest to use this esterified form as chemopreventive agent. Moreover several studies have been shown that polyphenols compounds such as resveratrol and viniferin have no effect on normal hematopoietic progenitor cells, in contrats to leukemic cells. Resveratrol as demonstrated specific cytotoxic effects toward tumor cells when 
compared with normal lung [31] and blood cells [32] (Clement et al, Blood 1998, 996-1002). At the concentrations inducing growth inhibition and cell cycle arrest in colon carcinoma cells, polyphenols compounds did not impair the viability of human normal peripheral blood mononuclear cells (PBMC) and much higher concentrations were required to induce a cytotoxic effect in these cells [10].

So, additional studies are now in progress to address the mechanisms by which vineatrol influences the cell cycle arrest and to define whether it modulates specific cyclins or Cyclindependent kinases involved in cell cycle progression. 
Acknowledgements:

This work was supported by the IFR Santé STIC (Inserm) and the Ligue Contre le Cancer, comité de Côte d’Or. 


\section{References}

[1] Renaud, S.C., Gueguen, R., Schenker, J. and d'Houtaud, A., Alcohol and mortality in middle-aged men from eastern France, Epidemiology. 1998, 9, 184-188.

[2] Delmas, D., Jannin, B. and Latruffe, N., Resveratrol: Preventing properties against vascular alterations and ageing, Mol Nutr Food Res. 2005, 49, 377-395.

[3] Delmas, D., Lancon, A., Colin, D., Jannin, B. and Latruffe, N., Resveratrol as a chemopreventive agent: a promising molecule for fighting cancer, Curr Drug Targets. 2006, 7, 423-442.

[4] Delmas, D., Passilly-Degrace, P., Jannin, B., Malki, M.C. and Latruffe, N., Resveratrol, a chemopreventive agent, disrupts the cell cycle control of human SW480 colorectal tumor cells, Int J Mol Med. 2002, 10, 193-199.

[5] Delmas, D., Rebe, C., Lacour, S., Filomenko, R., Athias, A., et al., Resveratrol-induced apoptosis is associated with Fas redistribution in the rafts and the formation of a death-inducing signaling complex in colon cancer cells, J Biol Chem. 2003, 278, 41482-41490.

[6] Schneider, Y., Vincent, F., Duranton, B., Badolo, L., Gosse, F., et al., Anti-proliferative effect of resveratrol, a natural component of grapes and wine, on human colonic cancer cells, Cancer Lett. 2000, 158, 85-91.

[7] Bernhard, D., Tinhofer, I., Tonko, M., Hubl, H., Ausserlechner, M.J., et al., Resveratrol causes arrest in the S-phase prior to Fas-independent apoptosis in CEM-C7H2 acute leukemia cells, Cell Death Differ. 2000, 7, 834-842.

[8] Fulda, S. and Debatin, K.M., Sensitization for anticancer drug-induced apoptosis by the chemopreventive agent resveratrol, Oncogene. 2004, 23, 6702-6711.

[9] Delmas, D., Rebe, C., Micheau, O., Athias, A., Gambert, P., et al., Redistribution of CD95, DR4 and DR5 in rafts accounts for the synergistic toxicity of resveratrol and death receptor ligands in colon carcinoma cells, Oncogene. 2004, 23, 8979-8986.

[10] Billard, C., Izard, J.C., Roman, V., Kern, C., Mathiot, C., et al., Comparative antiproliferative and apoptotic effects of resveratrol, epsilon-viniferin and vine-shots derived polyphenols (vineatrols) on chronic B lymphocytic leukemia cells and normal human lymphocytes, Leuk Lymphoma. 2002, 43, 1991-2002.

[11] Shang, X.Y., Wang, Y.H., Li, C., Zhang, C.Z., Yang, Y.C., et al., Acetylated flavonol diglucosides from Meconopsis quintuplinervia, Phytochemistry. 2006, 67, 511-515.

[12] Li, Y., Chen, X., Satake, M., Oshima, Y. and Ohizumi, Y., Acetylated flavonoid glycosides potentiating NGF action from Scoparia dulcis, J Nat Prod. 2004, 67, 725-727.

[13] Okasaka, M., Takaishi, Y., Kogure, K., Fukuzawa, K., Shibata, H., et al., New stilbene derivatives from Calligonum leucocladum, J Nat Prod. 2004, 67, 1044-1046.

[14] Munkombwe, N.M., Acetylated phenolic glycosides from Harpagophytum procumbens, Phytochemistry. 2003, 62, 1231-1234.

[15] Riva, S., Monti, D., Luisetti, M. and Danieli, B., Enzymatic modification of natural compounds with pharmacological properties, Ann N Y Acad Sci. 1998, 864, 70-80.

[16] Kang, J.H., Park, Y.H., Choi, S.W., Yang, E.K. and Lee, W.J., Resveratrol derivatives potently induce apoptosis in human promyelocytic leukemia cells, Exp Mol Med. 2003, 35, 467-474.

[17] Kim, H.J., Chang, E.J., Bae, S.J., Shim, S.M., Park, H.D., et al., Cytotoxic and antimutagenic stilbenes from seeds of Paeonia lactiflora, Arch Pharm Res. 2002, 25, 293-299.

[18] Yamada, M., Hayashi, K., Ikeda, S., Tsutsui, K., Tsutsui, K., et al., Inhibitory activity of plant stilbene oligomers against DNA topoisomerase II, Biol Pharm Bull. 2006, 29, 1504-1507.

[19] Lambert, J.D., Sang, S., Hong, J., Kwon, S.J., Lee, M.J., et al., Peracetylation as a means of enhancing in vitro bioactivity and bioavailability of epigallocatechin-3-gallate, Drug Metab Dispos. 2006, 34, 21112116.

[20] Bernhard, D., Schwaiger, W., Crazzolara, R., Tinhofer, I., Kofler, R., et al., Enhanced MTT-reducing activity under growth inhibition by resveratrol in CEM-C7H2 lymphocytic leukemia cells, Cancer Lett. 2003, 195, 193-199.

[21] Mosmann, T., Rapid colorimetric assay for cellular growth and survival: application to proliferation and cytotoxicity assays, J Immunol Methods. 1983, 65, 55-63.

[22] Marshall, N.J., Goodwin, C.J. and Holt, S.J., A critical assessment of the use of microculture tetrazolium assays to measure cell growth and function, Growth Regul. 1995, 5, 69-84.

[23] Yeh, C.J., Hsi, B.L. and Faulk, W.P., Propidium iodide as a nuclear marker in immunofluorescence. II. Use with cellular identification and viability studies, J Immunol Methods. 1981, 43, 269-275.

[24] Delmas, D., Jannin, B., Malki, M.C. and Latruffe, N., Inhibitory effect of resveratrol on the proliferation of human and rat hepatic derived cell lines, Oncol Rep. 2000, 7, 847-852.

[25] Cardile, V., Lombardo, L., Spatafora, C. and Tringali, C., Chemo-enzymatic synthesis and cell-growth inhibition activity of resveratrol analogues, Bioorg Chem. 2005, 33, 22-33. 
[26] Fragopoulou, E., Nomikos, T., Karantonis, H.C., Apostolakis, C., Pliakis, E., et al., Biological activity of acetylated phenolic compounds, J Agric Food Chem. 2007, 55, 80-89.

[27] Hua, J., Sheng, Y., Bryngelsson, C., Kane, R. and Pero, R.W., Comparison of antitumor activity of declopramide (3-chloroprocainamide) and N-acetyl-declopramide, Anticancer Res. 1999, 19, 285-290.

[28] Pagliacci, M.C., Spinozzi, F., Migliorati, G., Fumi, G., Smacchia, M., et al., Genistein inhibits tumour cell growth in vitro but enhances mitochondrial reduction of tetrazolium salts: a further pitfall in the use of the MTT assay for evaluating cell growth and survival, Eur J Cancer. 1993, 29A, 1573-1577.

[29] Ulrich, S., Loitsch, S.M., Rau, O., von Knethen, A., Brune, B., et al., Peroxisome Proliferator-Activated Receptor \{gamma as a Molecular Target of Resveratrol-Induced Modulation of Polyamine Metabolism, Cancer Res. 2006, 66, 7348-7354.

[30] Golstein, P. and Kroemer, G., Cell death by necrosis: towards a molecular definition, Trends Biochem Sci. 2007, 32, 37-43.

[31] Lu, J., Ho, C.H., Ghai, G. and Chen, K.Y., Resveratrol analog, 3,4,5,4'-tetrahydroxystilbene, differentially induces pro-apoptotic p53/Bax gene expression and inhibits the growth of transformed cells but not their normal counterparts, Carcinogenesis. 2001, 22, 321-328.

[32] Clement, M.V., Hirpara, J.L., Chawdhury, S.H. and Pervaiz, S., Chemopreventive agent resveratrol, a natural product derived from grapes, triggers CD95 signaling-dependent apoptosis in human tumor cells, Blood. 1998, 92, 996-1002. 


\section{Figure legends}

Figure 1. Inhibitory effects of resveratrol and analogues on the proliferation of SW480 cells. (A) Chemical structures of polyphenol compounds. (B) and (D) After 24h of culture, SW480 cells were treated with medium containing the solvent $(0.1 \%$ ethanol) or the compounds. Treated and control cells were harvested at 0, 24, 48, 72 and 96h. Cell proliferation was quantified with a haemocytometer. Viable and dead cells were distinguished by trypan blue exclusion. C) After treatment as in B), cell number was determined with a Coulter counter. (E) Dead cells (\%) were determined by flow cytometry after staining with PI. (B, C D, E: mean \pm S.D. of three independent experiments).

Figure 2. Concentration-dependent inhibition of colon cancer cell proliferation with resveratrol and analogue compounds. (A) After 24h of culture, cells were incubated with or without compounds during 48 (black curve), 72 (blue curve) and 96h (red curve). Then colorimetric proliferative MTT test was used and the absorbance was measured after 3h of incubation at $37^{\circ} \mathrm{C}$. Results were expressed as percentage of control values. Values correspond to the mean \pm S.D. (n=6). (B) . (B) Dose-dependence of MTT reduction by polyphenolic compounds during 4, 8 and 24 h of incubation in a range concentrations ( $\square 3$ $\mu \mathrm{M}, 30 \mu \mathrm{M}, \square 60 \mu \mathrm{M}, \mathbf{\square} 100 \mu \mathrm{M}$ ). Vitamin C was used as positive control. (A \& B: mean \pm S.D. of three independent experiments). (C) SW480 cells were untreated (Ctl) or treated with resveratrol and analogue compounds for 48 h before nuclear staining with Hoechst 33342. Original magnification : x 50. (D) SW480 cells were untreated or treated with resveratrol and analogue compounds for $48 \mathrm{~h}$ before staining with blue trypan or Hoechst 33342 (mean \pm SE of 3 independent experiments in which each percentage was calculated by counting 300 cells). Figure 3. Analysis of polyphenol compounds effects on cell cycle profiles in SW480 cells. After $24 \mathrm{~h}$ of culture, cells were incubated with or without Rs, Ra, R3A, $\varepsilon V, \varepsilon V 5 A(30 \mu \mathrm{M})$ and Vinea5 (5 $\mu \mathrm{M}$ resveratrol) for 24,48 or $72 \mathrm{~h}$. Cells were collected and analyzed by flow 
cytometry after staining with PI. One representative of three independent experiments is shown.

Figure 4. Quantitative analysis of the distribution of cells in the phases of the cell cycle (mean \pm S.D. of three independent experiments).

Figure 5. Analysis of vineatrol effects on cell cycle profiles in SW480 cells. As in Fig. 3, after $24 \mathrm{~h}$ of culture, cells were incubated with or without polyphenol compounds during 24 , 48 or $72 \mathrm{~h}$. Rs was used at $30 \mu \mathrm{M}$ and vineatrol was used with a range of resveratrol equivalent $\mu \mathrm{M}$. One representative of three independent experiments is shown.

Figure 6. Quantitative analysis of the distribution of cells in the phases of the cell cycle (mean \pm S.D. of three independent experiments).

Figure 7. Time course of DNA synthesis analysis in SW480 cells. After 24h of culture, cells in proliferative state were incubated with or without Rs, Ra, R3A, $\varepsilon V, \varepsilon V 5 A(30 \mu \mathrm{M})$ Vinea10 (10 $\mu \mathrm{M}$ resveratrol) and Vinea30 (30 $\mu \mathrm{M}$ resveratrol) during 24, 48 or $72 \mathrm{~h}$. Radioactivity was corrected according to the cell number cycle (mean \pm S.D. of three independent experiments). 
Figure 1

A)<smiles>Fc1cc(F)cc(/C=C/c2ccc(I)cc2)c1</smiles>

$\mathrm{R}=\mathbf{O H}$; Resveratrol $(\mathrm{R})$

$\mathrm{R}=\mathrm{CH3COO}$; Resveratrol triacetate (R3A)

B)

mbe 7

$r$ of

cells 6

per 5

well

(x10 4

6) 3

(Try

pan 2

blue 1

excl

usio 0

$\begin{array}{llllll}\text { n) } & 0 & 24 & 48 & 72 & 96\end{array}$

Time of treatment (hours)

C)

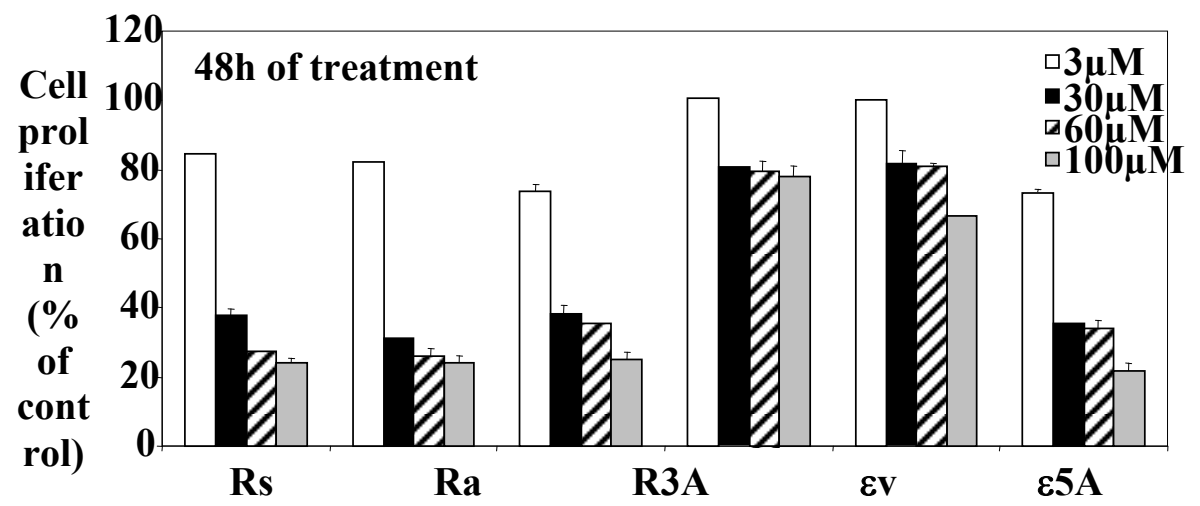

E)

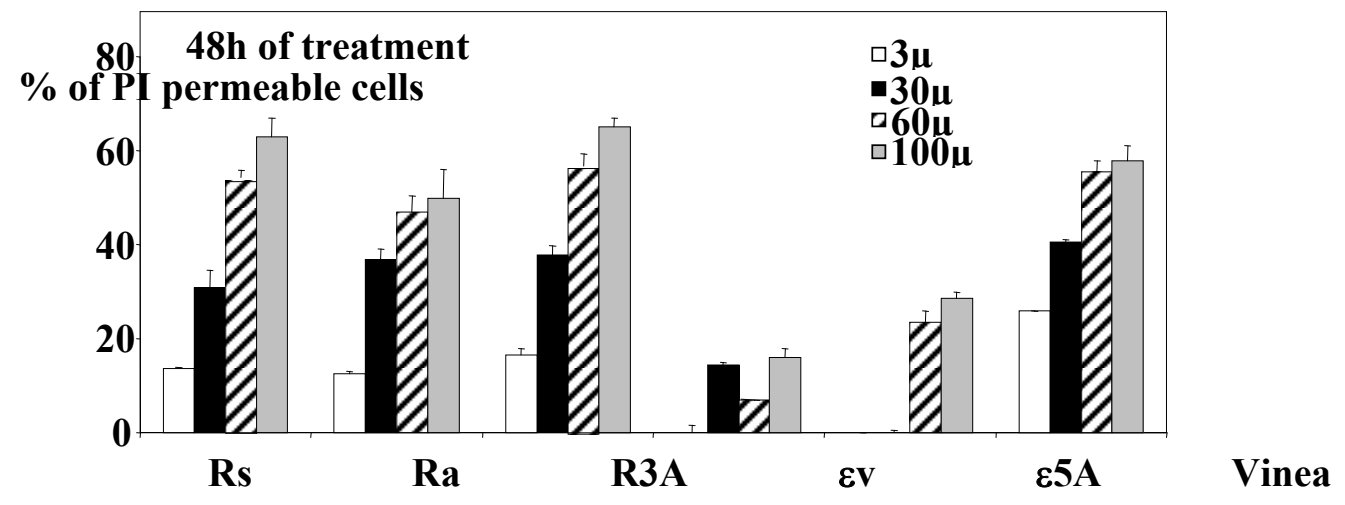

$\varepsilon$-Viniferin

D)

$\mathrm{R}=\mathrm{OH} ; \varepsilon$-Viniferin $(\varepsilon \mathrm{V})$

$\mathrm{R}=\mathrm{CH3COO}$;

pentaacetate $(\varepsilon \mathrm{V} 5 \mathrm{~A})$

7

Numbrer of cells per well (x10\%) $\bullet_{\mathrm{Ctl}}$

(trypan blue exclusion) $\quad$ Rs

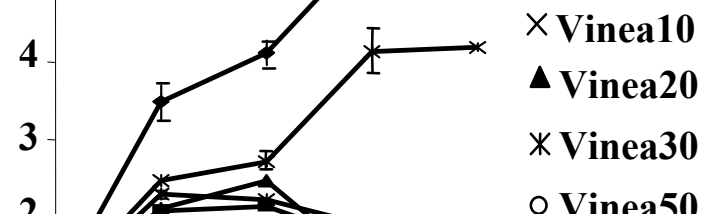

0

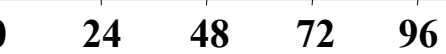

Time of treatment (hours) 
Figure 2

A)

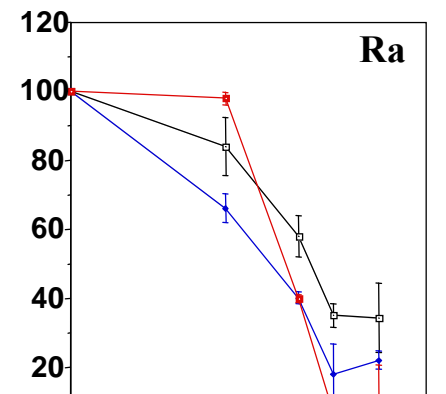

$\%$ MTT-reducing activity (Succinate DH activity)
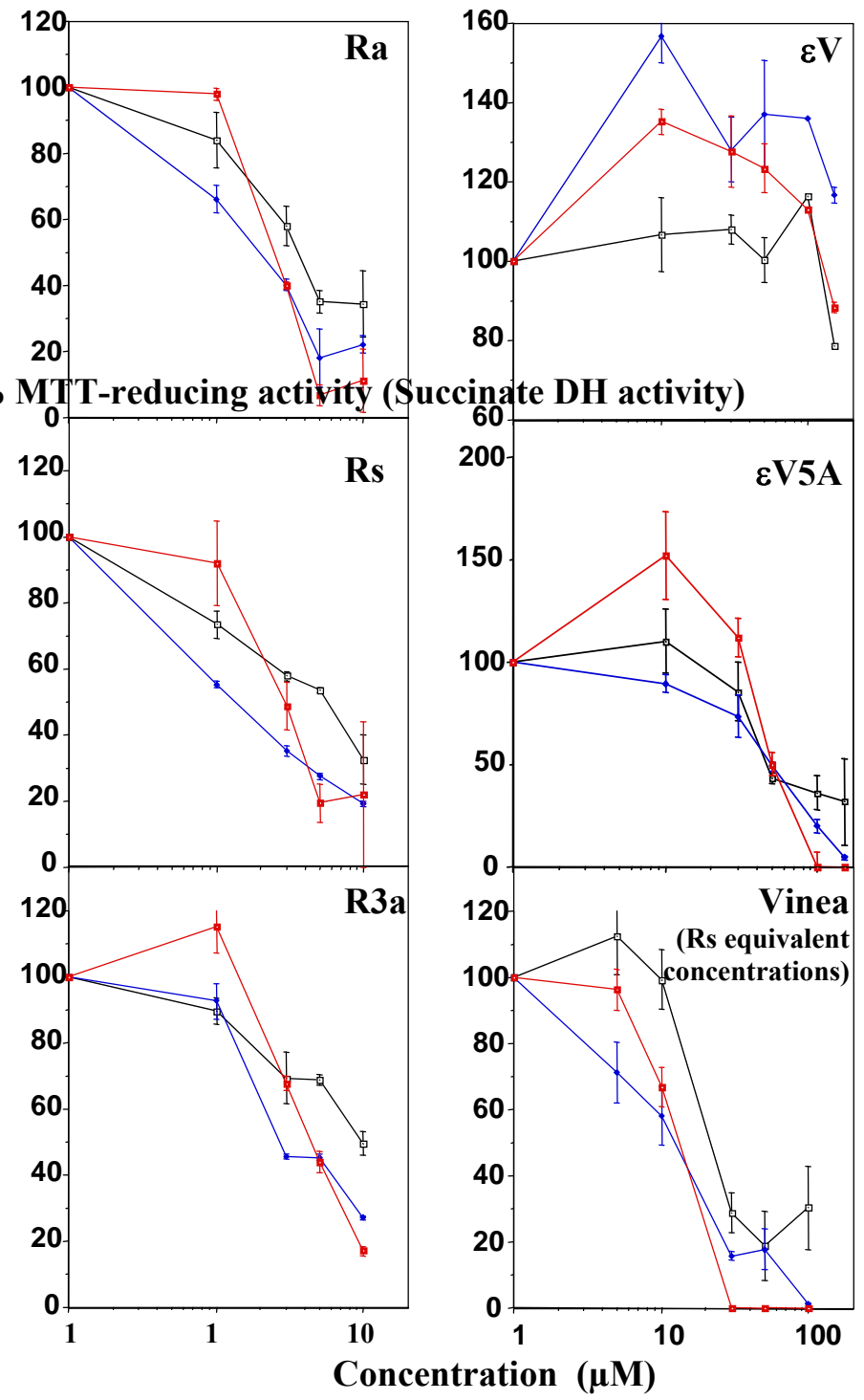

B)
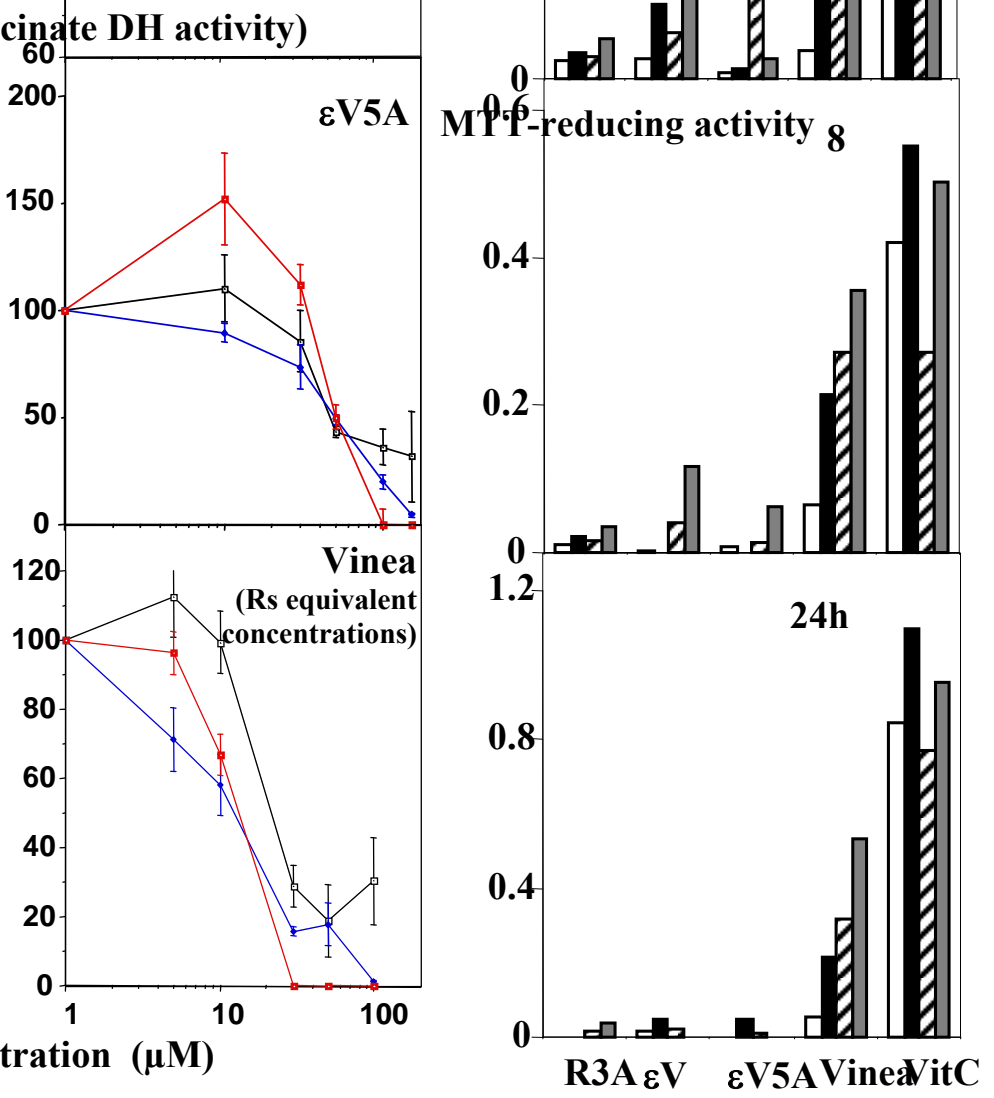

C)

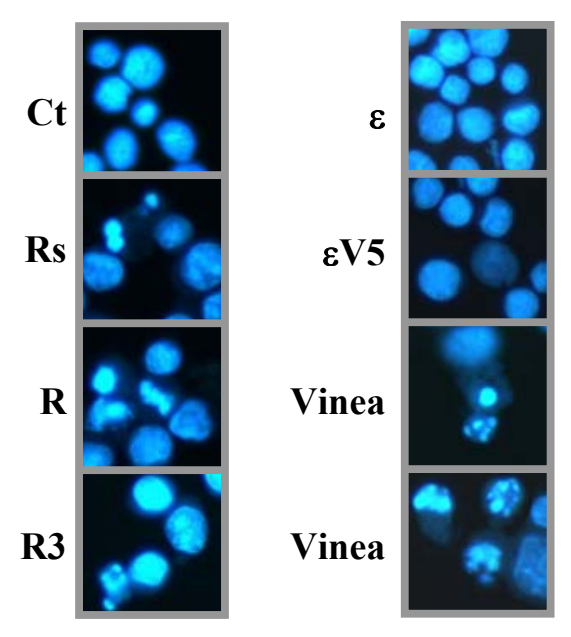

D)

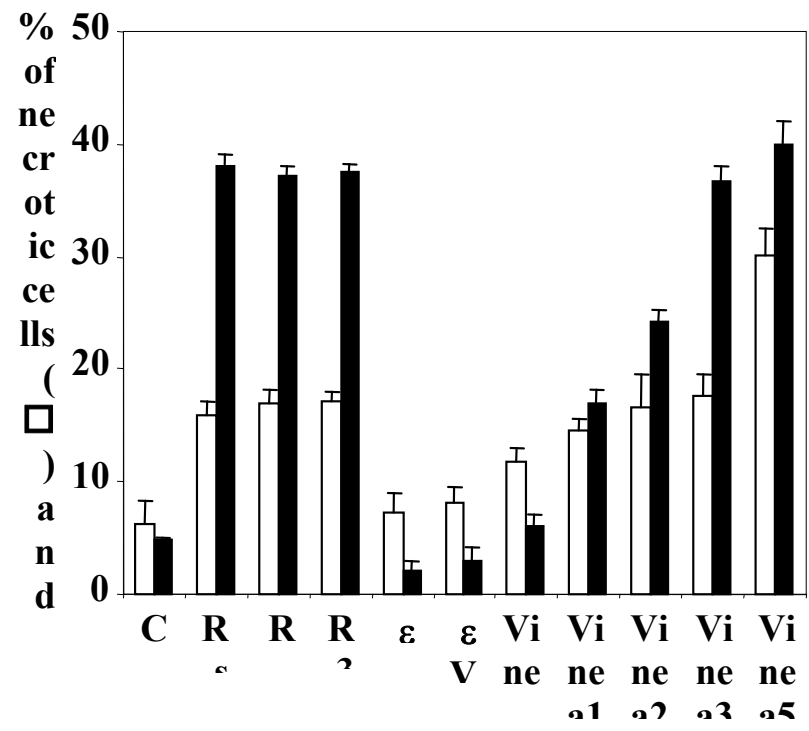


Figure 3

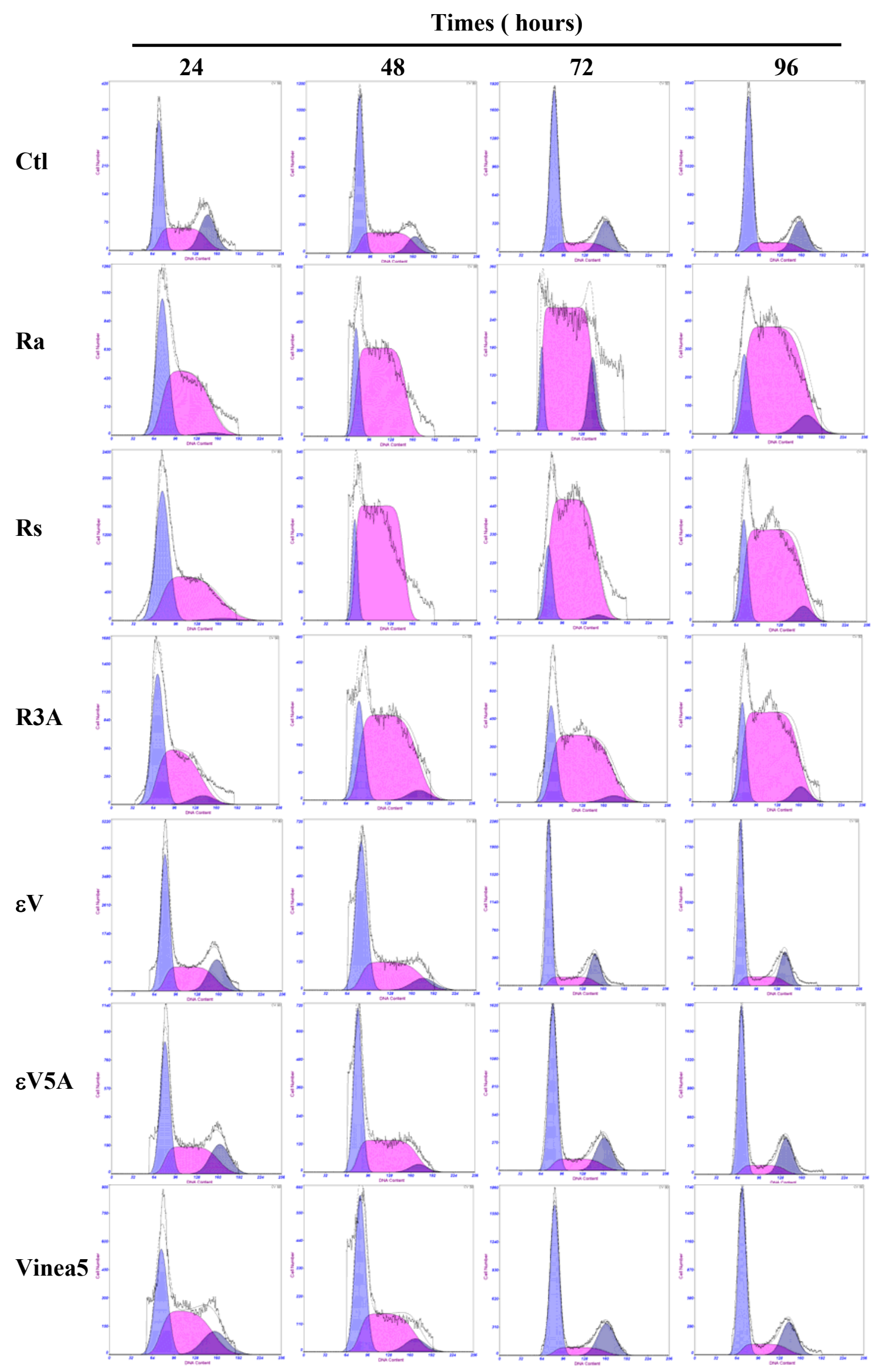


Figure 4

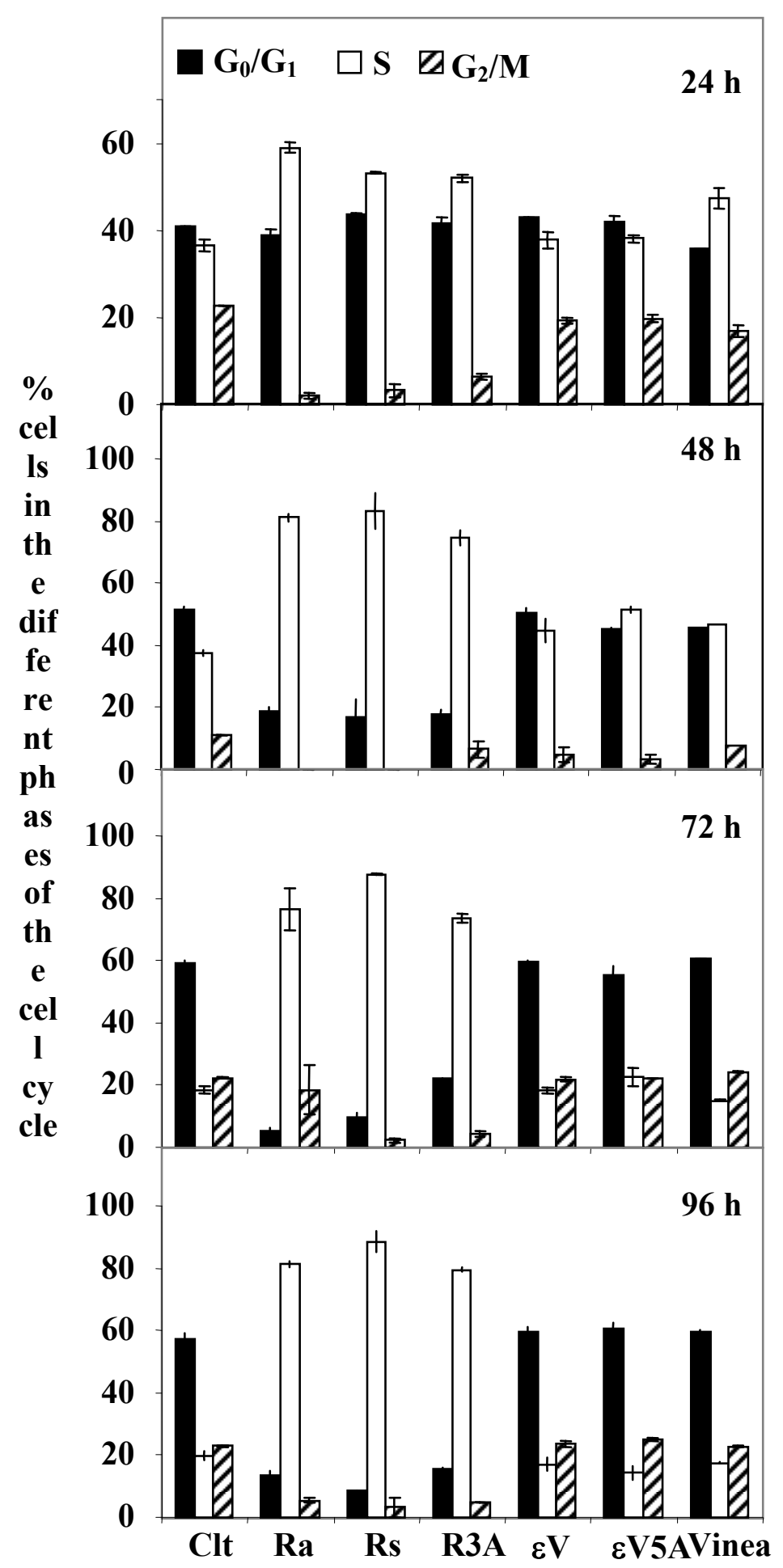


Figure 5

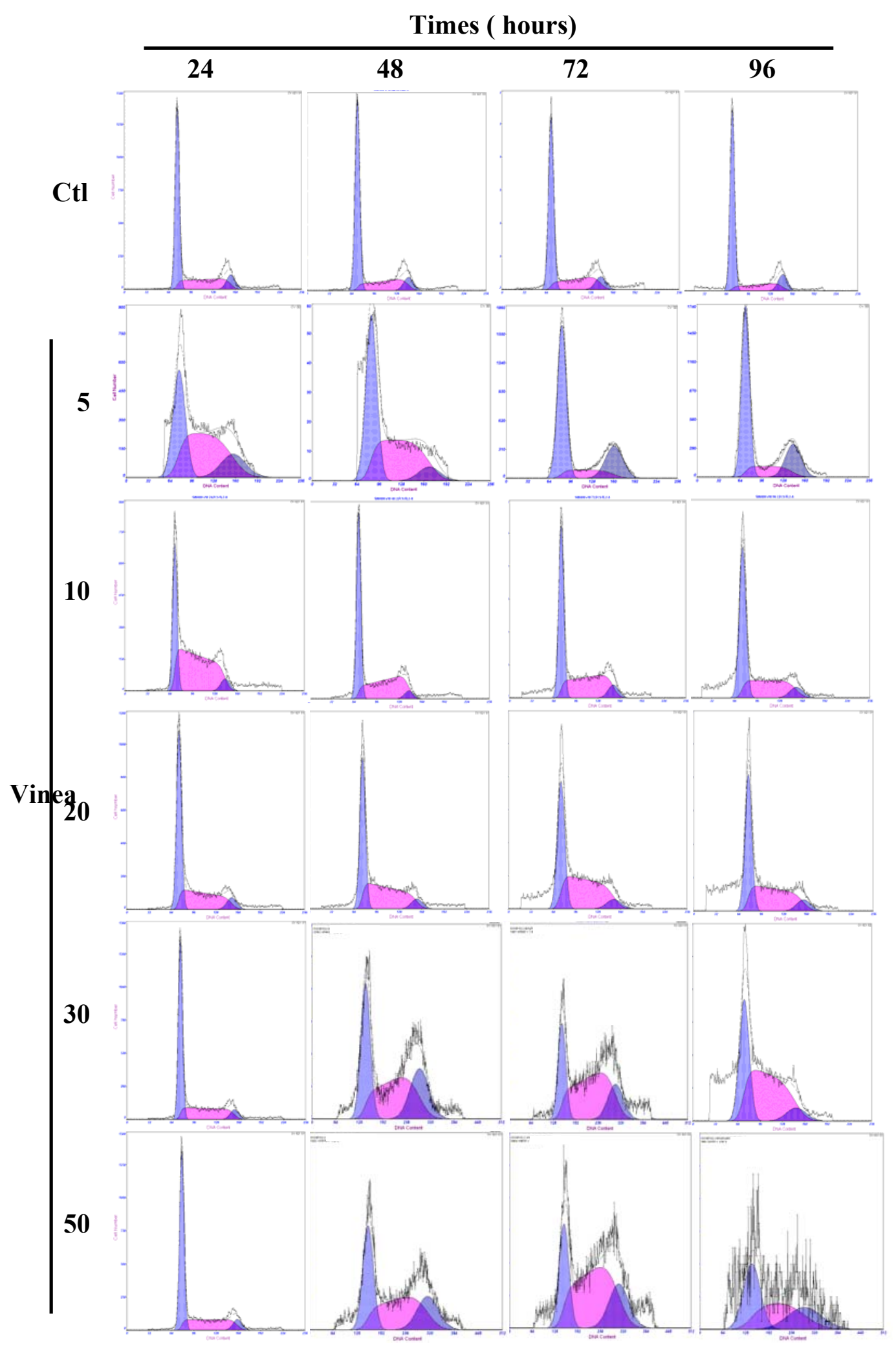


Figure 6

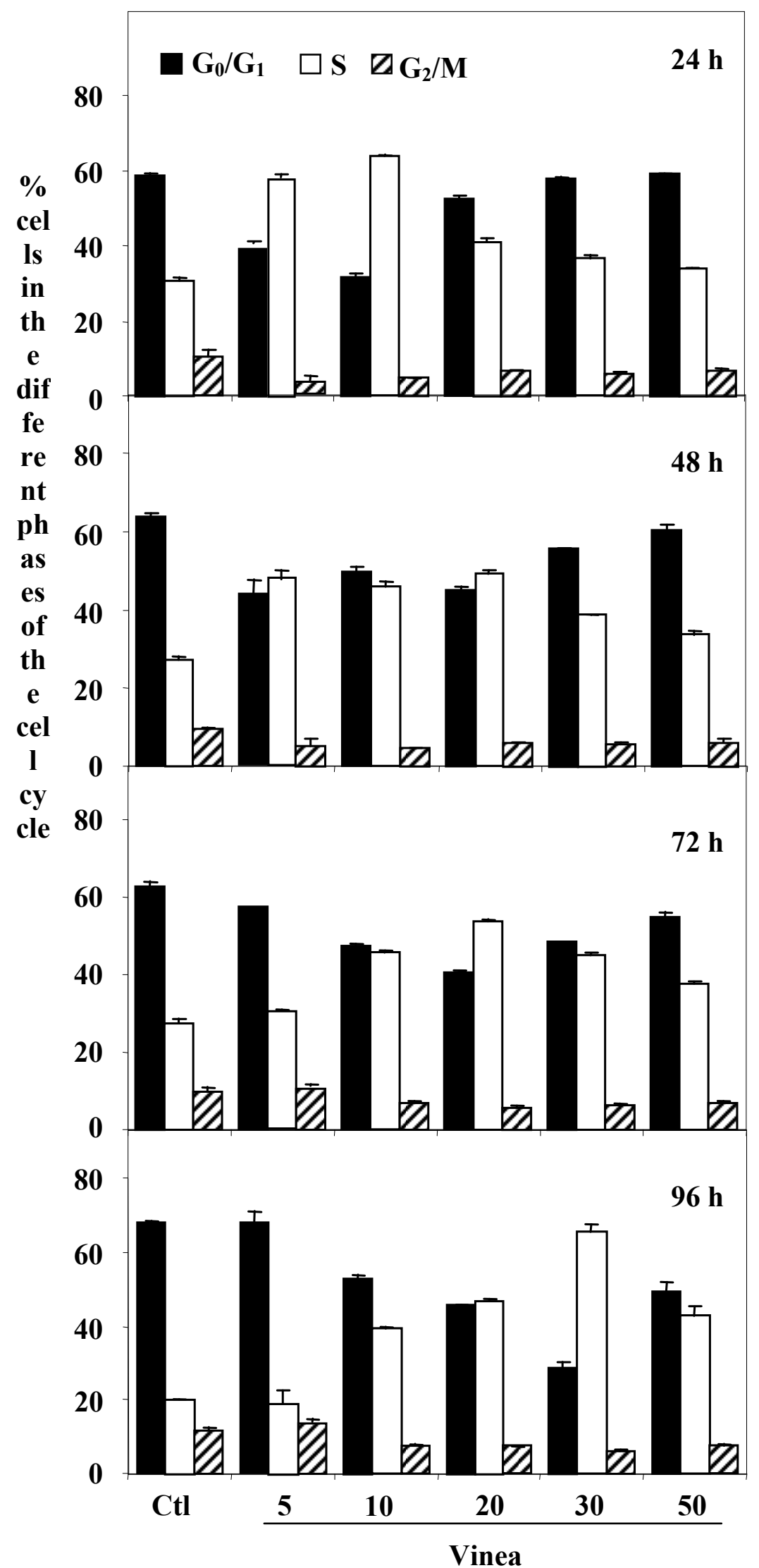


Figure 7

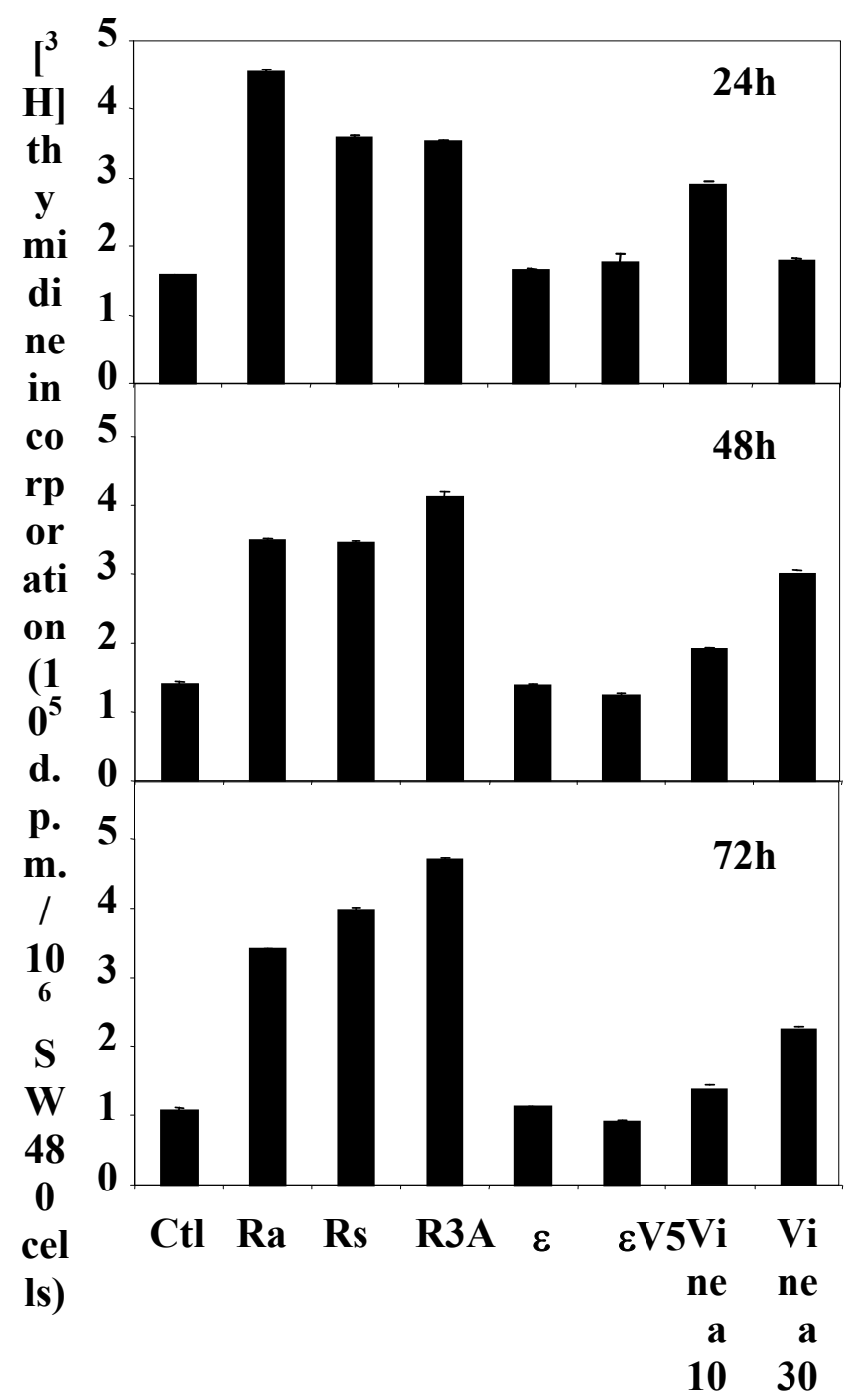


